مجلة العلوم الهندسية_العدد الثاني-2006

\title{
Developing a Geographic Information System (GIS) for North of Khartoum State
}

\author{
Dr. Fathi M. Mohammed Saied*
}

\begin{abstract}
This paper describes the techniques used to develop a GIS model for the north rural region of Khartoum State. The developed model was based on remote sensing and GIS integration. A wide range of procedures was applied to make use of the GIS activities to model both land-use and land Cover in the study area, to find solutions and a room for developing the study area towards a future situations where most of the problems arising from the current situation are solved. The developed GIS model represents different digital topographic and thematic maps. Land-use activities associated with their attributes database have been highlighted where answers for frequently asked questions can be obtained. The answers can be represented in hard copy (maps), reports, charts, tabular data, or in digital formats.
\end{abstract}

ملخص

تتناول هذه الورقة الدراسات والتقنيات التى استخدت فى اعداد نموزج نظام دعلومات جغرافية لمنطقه دراسه

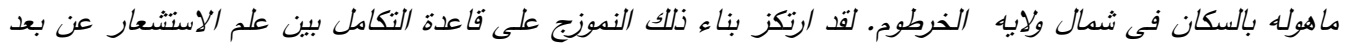

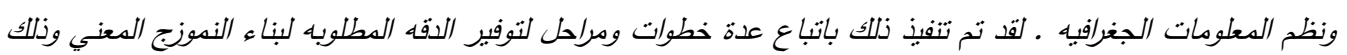

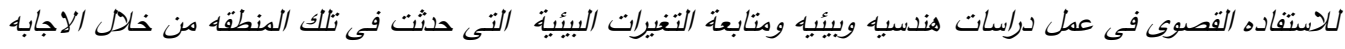

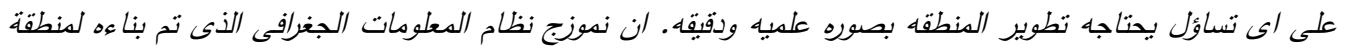

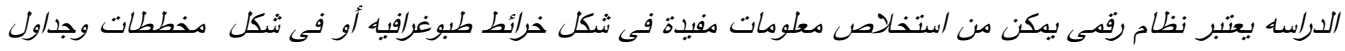
تساعد في اتخاذ القرار لكل متطلبات التتسية من تخطيط عمرانى أو اعادة تخطيط عدرانى أو أوخلافه.

* Asst.Prof. Omdurman Islamic University-Faculty of Engineering Sciences.

\section{Introduction}


Developing a Geographic Information System (GIS)... Dr.Fathi M. Mohammed Saied

It was very long time ago since human activities include organizing spatial distribution attributes of the earth's surface. This involved acquiring data about resources, animals, plants, and people. These data are used to be organized in map forms and reports in a nice representation.. Remote sensing and Geographical information are two integrative Systems. Each system is being perfected in its own way.

The interest in remote sensing technology has been paralleled in other international development agencies. Virtually, every bilateral development assistance program has expertise in the field of natural resource survey and inventory methodologies. Many governments have established permanent remote sensing and GIS unites. Remote sensing capabilities were to be a twenty first century information system which lead to the growth of a new global earth information industry, which will use map (accurate) and information (rich imagery) to revolutionize the way people conduct jobs. The launch of the new generation of very high resolution commercial satellites began in early 1998 such as IKONOS of the USA.

GIS existed as early as earlier Muslims such as Ibin Batotah traveling to different places over the world and describing their findings. They used to relate the description information to the geographic locations. Too many geographic related information presented in simple drawing to guide the advancement of ground troops of the Islamic Empire to spread Islam and educate human being (1400 years ago) (Al Garni, 1994). Almost 30 years ago, a number of geographers conceived a system for storing, and organizing spatial information in a computer. Over the past decade, this growing technology has come to be known as a GIS. Paralleling advancements in the technology has been the growth of GIS applications. From high quality cartography to land used planning, task mapping, ecological research, demographic research, utilities, business application and more. GIS is one of the longest computer applications over to emerge (Carter-1996).

\section{Study Area}


The rural region of Khartoum North was selected as a test area for the present experiment.

The study area lies between latitudes $15^{\circ} 41^{\prime} 00^{\prime \prime}, 15^{\circ} 45^{\prime} 00^{\prime \prime} \mathrm{N}$ and longitudes $32^{\circ} 30^{\prime} \quad 00^{\prime \prime}, 32^{\circ} 34^{\prime} 00^{\prime \prime}$ E .It is one of the regions witnessing rapid changes and development. Until 1984 the area was covered with few human activities and different types of land cover such as water bodies (the River Nile), vegetations, cultivated areas, drainage and other natural features.

\section{Procedures, Results and Analysis of the Test}

a) The primary data used in this study are an analog line map at scale of 1: 25000 produced by the Topographic and Aerial Photography Administration in 1984, Satellite Imagery acquired by IKONOS imaging system in the year2003, Spot-4 (2001), Landsat-7 (2000) and a colored aerial photograph (Figures 1-5). Attribute data was collected from existing maps, other official sources and field observations.

b) The test was carried out in a PC-Pentium III, $800 \mathrm{MHz}$ with 512 MB Ram. A4 plotter was used to print out the results of this research work. Arc/Info and ArcView as professional GIS software packages were used to manage, Process and model the GIS system. AutoCAD was used to digitize the line map of the study area, IDRISI, ERDAS, and ILWIS were used to process the remotely sensed data to extract useful information..

c) The experimental test was carried out in three phases. Phase one was concerns with the preprocessing and the management of data where the objective of producing different thematic coverage of the study area was achieved. In phase two, digital image-processing techniques have been applied to produce land-use and land-cover maps of the study area. In the last phase a GIS model was created.

d) Since the data available are composed of different formats and have been acquire from different sources and different systems, 
$\underline{\text { Developing a Geographic Information System (GIS)... Dr.Fathi M. Mohammed Saied }}$

the first step was to check the accuracy of these data and then to bring them to a common geo-reference (UTM).

Landsat and SPOT images as well as an aerial photo graph covering the study area have been projected to a state plane grid (map grid) while IKONOS data have been projected to a UTM grid based on weak control points. This was very clear that from the early processing phase where a constant shift was detected by comparing data with existing maps of the study area.

The analog map of the study area was transformed to UTM grid (Adindan datum) based on well-distributed control points. ILWIS and ERDAS programs were used to transform the IKONOS data coordinate system to a UTM coordinate system based on control points drove from the analog map grid.

To make use of the remotely sensed data in a composite form all spectral bands of these data [15bands detailed as follows (6Landsat bands, 3Spot bands, 3IKONOS bands, and 3 colored aerial photos bands)], were Re-sampled to IKONOS spatial resolution $(1 \mathrm{~m})$.

e) The line map of the study area was digitized to generate landuse and land-cover features. Nine layers were generated and exported as a DXF file (Figure4). Secondary data was imported into Arc/Info environment where topology for each cover was constructed.

f) Remotely sensed data was subjected to digital enhancement techniques where all spectral bands have been linearly stretched to fit the full dynamic range $(0-255)$.

g) Different land use and thematic information have been extracted by digitizing the raster map (FCC) directly from the screen ILWIS 3.0 editor was found to be useful for such a purpose. The digitized data were exported as ARC/INFO coverage where topology was again constructed for all coverage. The same data management and geometric correction process carried out on the previous session were again applied to all covers generated from the remotely sensed data. 
h) Before generating the GIS model of the study area, overlay process was carried out to estimate the urban growth, the agriculture growth, and water changes (Figure 8-10), during the period from 1984 to 2003.

The covers, which define urban features of 1984 and 2003, were subjected to further analysis process. The coverage data of 1984 was erased from that of 2003. The resulted output coverage represents the urban growth, taken place during the period from 1984 up to 2003.

The same procedures have been repeated with the corresponding covers, which define agriculture and water features.

i) To assess the potentiality of the GIS model for re-planning process, Elhalfaia town was selected as a pilot project for that purpose. New proposed roads have been allocated inside the town area according to the basic planning specifications.

A buffer processing (10 meters, Sudanese Town Planning Specifications) in width was carried out based on the new road coverage. The buffer coverage was erased from the land use map of the study area. The produced coverage, in that way defines the new situation of the Elhalfaia town.

j) ArcView was used to generate the digital GIS model of the study area (Figure 11). Each view represents either land use themes or land cover thematic information. Solutions generated from the analysis session have been added to the model as new themes. The created model is a dynamic one, where new features and data could be added, query and analysis processing may be carried out for predicting answers for future questions concerning different land use and land cover aspects.

k). The classified raster image of the study area, produced by applying digital classification techniques to the test data(Figure 12), has been subjected to further ground checks. This was carried out to verify the extent to which the classification results meet the objectives of this study. 
$\underline{\text { Developing a Geographic Information System (GIS)... Dr.Fathi M. Mohammed Saied }}$

A hard copy of the classified image was printed out for field check purposes. The ground coordinates of predetermined train sites have been picked out from the digital GIS model of the study area. These sites representing the spectral signature of the classification domain resulted from the classification process carried throughout the test.

A GPS receiver (Garmin 12XL with $\pm 13 \mathrm{~m}$ planimmetric accuracy), was used, as a navigator tool, to allocate the corresponding ground positions of the train sites. Figure 13 shows a final classified image based on the fieldwork verification process, while Table (1) gives the output results of the ground truth checks.

\section{Conclusions}

1. Remote sensing and GIS integration was a useful issue in developing the GIS model of the study area.

2. Different thematic map, have been produced based on remotely sensed data as well as existing documents.

3. The developed GIS model can answer different questions such as the estimation of the urban growth in the study area, the replanning analysis of the study area.

4. The developed GIS model offers great activities in monitoring and detecting environmental changes.

5. As tested, digital image processing and digital mapping overall, have contributed tremendously to overcoming various problems arising from the lack of up-to-date information. In fact it can certainly be concluded that, traditional means have no role to play in renewing and revising the old mapping system in Sudan.

6. IKONOS imaging system with its high ground resolution (one meter) open a wide gate for space mapping at large scales. This is especially true as tested in this study. In this way satellite remote sensing offers solutions for the sever problems arising when the main issue is mapping a large area such as the case in Sudan. 


\section{References}

[1] Lillesand and Kiefer Third Edition 1994: Remote Sensing and Image Interpretation

[2] Ray Harris 1987: Satellite Remote Sensing.

[3] Jacobsen K. 2002. Mapping with IKONOS Images 2002.

[4] Wolf P.R. 6 ${ }^{\text {th }}$. Principles of Surveying Edition 1997.

[5] Carter -1996: Fundamentals of Geographical Information System (GIS).

[6] Gerlach, F., 2000 Characteristics of Space Imaging One - Meter Resolution Satellite Imagery Products.

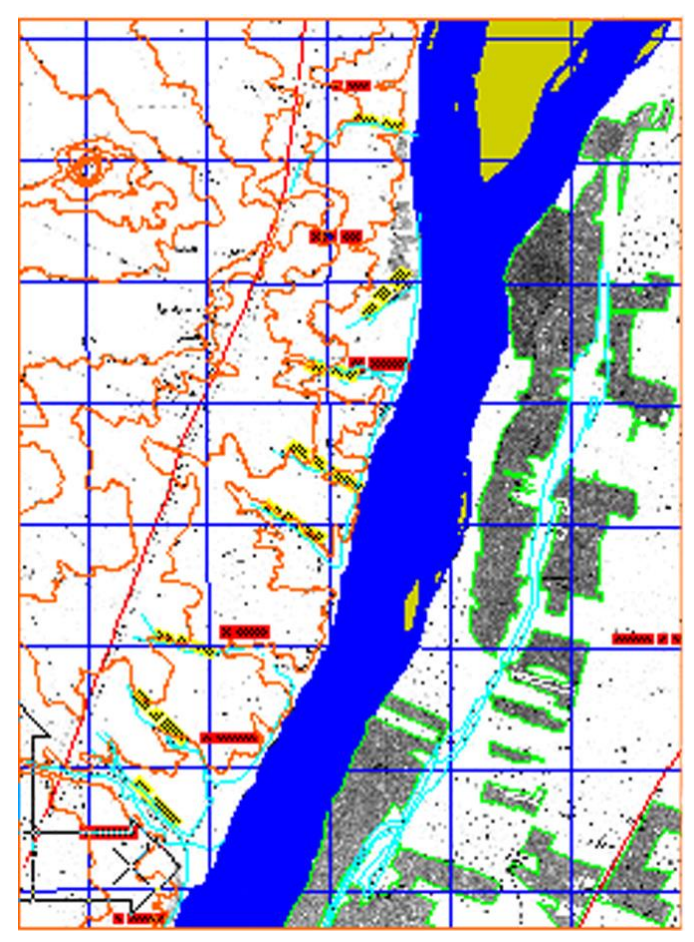

Figure (1) An Analog Line Map of the Study Area 
$\underline{\text { Developing a Geographic Information System (GIS)... Dr.Fathi M. Mohammed Saied }}$

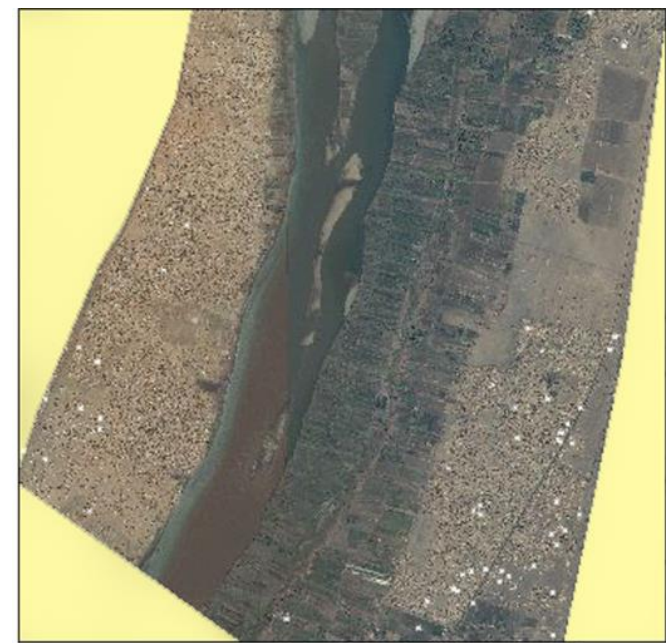

Figure (2) IKONOS imaging system data (2003) - Bands RGB $(1,2,3)$ for the Study Area

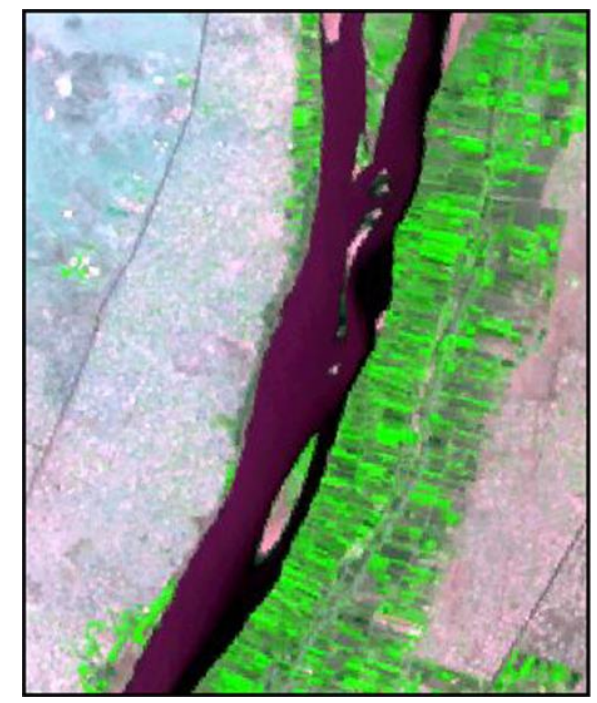

Figure 3(a) Spot-4 (2001) data

Natural Color Composite Bands RGB (XS2, XS3, XS1)

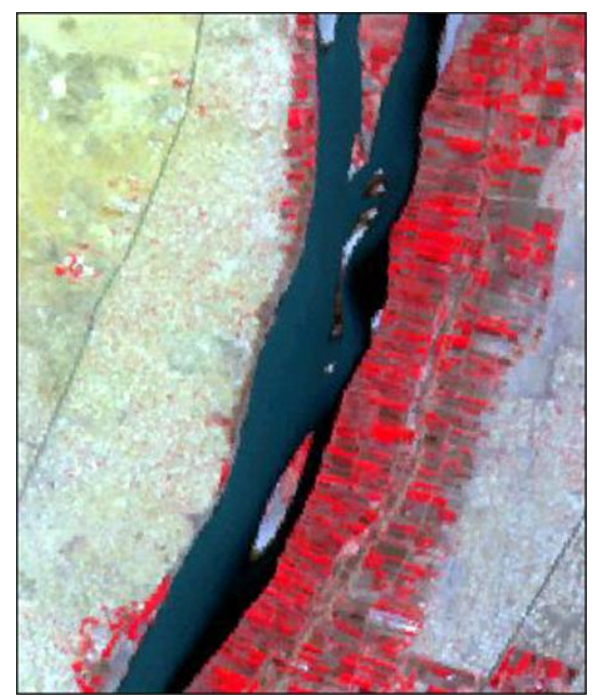

Figure 3(b) Spot- 4 (2001) data

False Color Composite Bands RGB (XS1, XS2, XS3) 
for the Study Area.

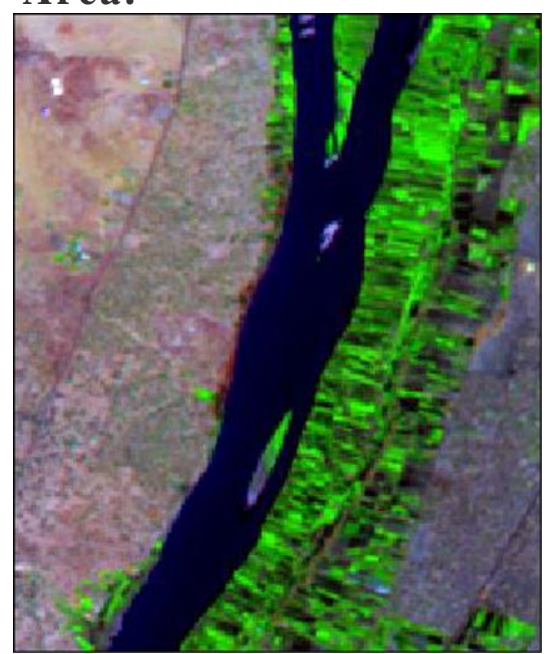

Figure 4 Landsat-7 (2000) data

Natural Color Composite - Bands RGB (5, 4, 2)

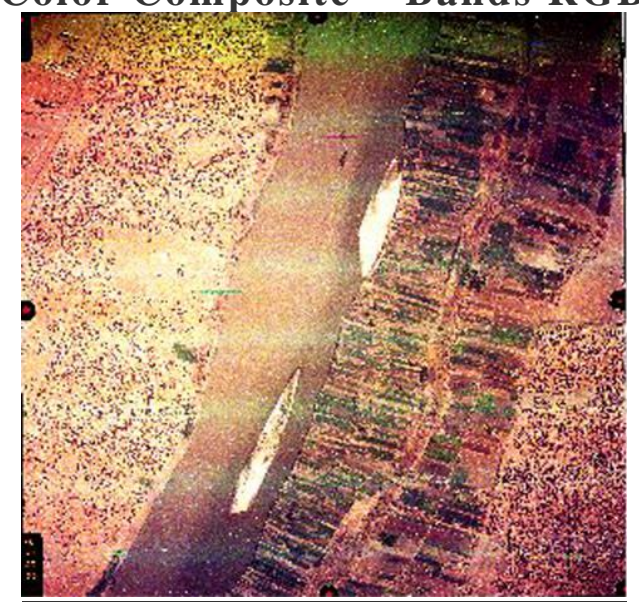

Figure 5 Colored Aerial Photograph (2002)-Bands RGB $(1,2$, and 3$)$ 
$\underline{\text { Developing a Geographic Information System (GIS)... Dr.Fathi M. Mohammed Saied }}$

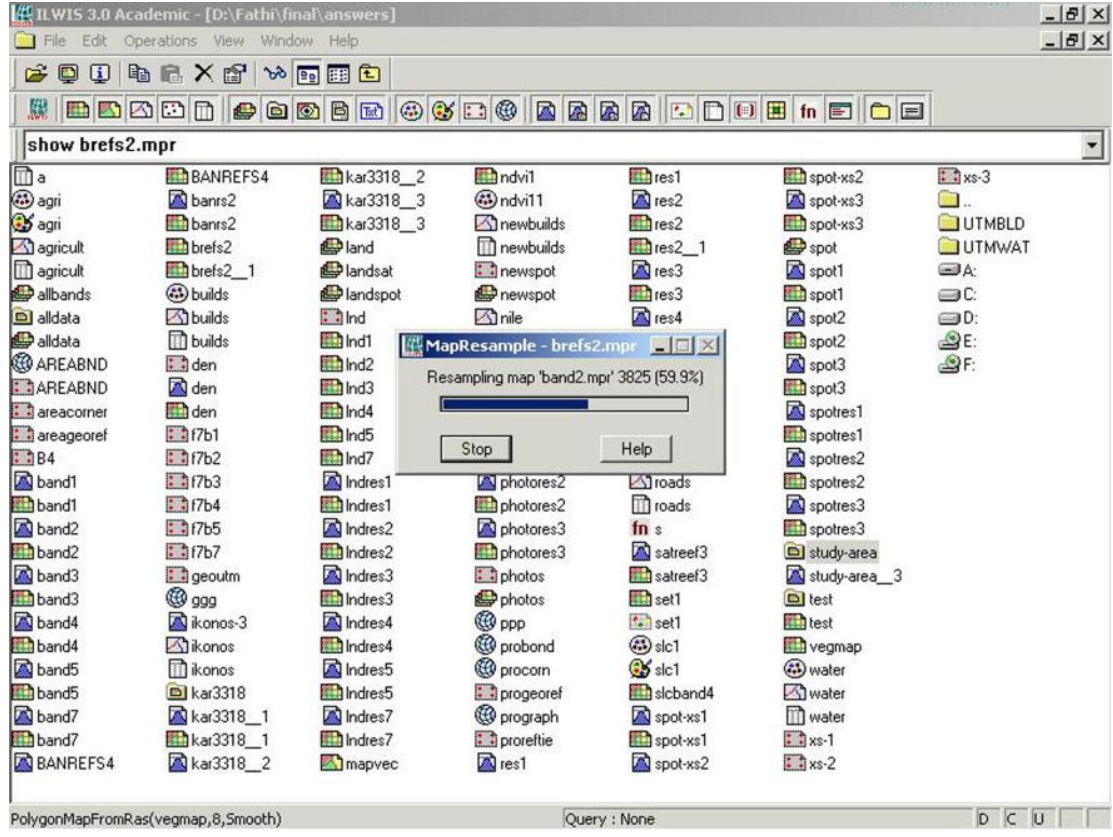

Figure (6) The Re-sampling Process of Land sat Band2To IKONOS Bands for The Study Area 
مجلة العلوم الهندسية_العدد الثاني-2006

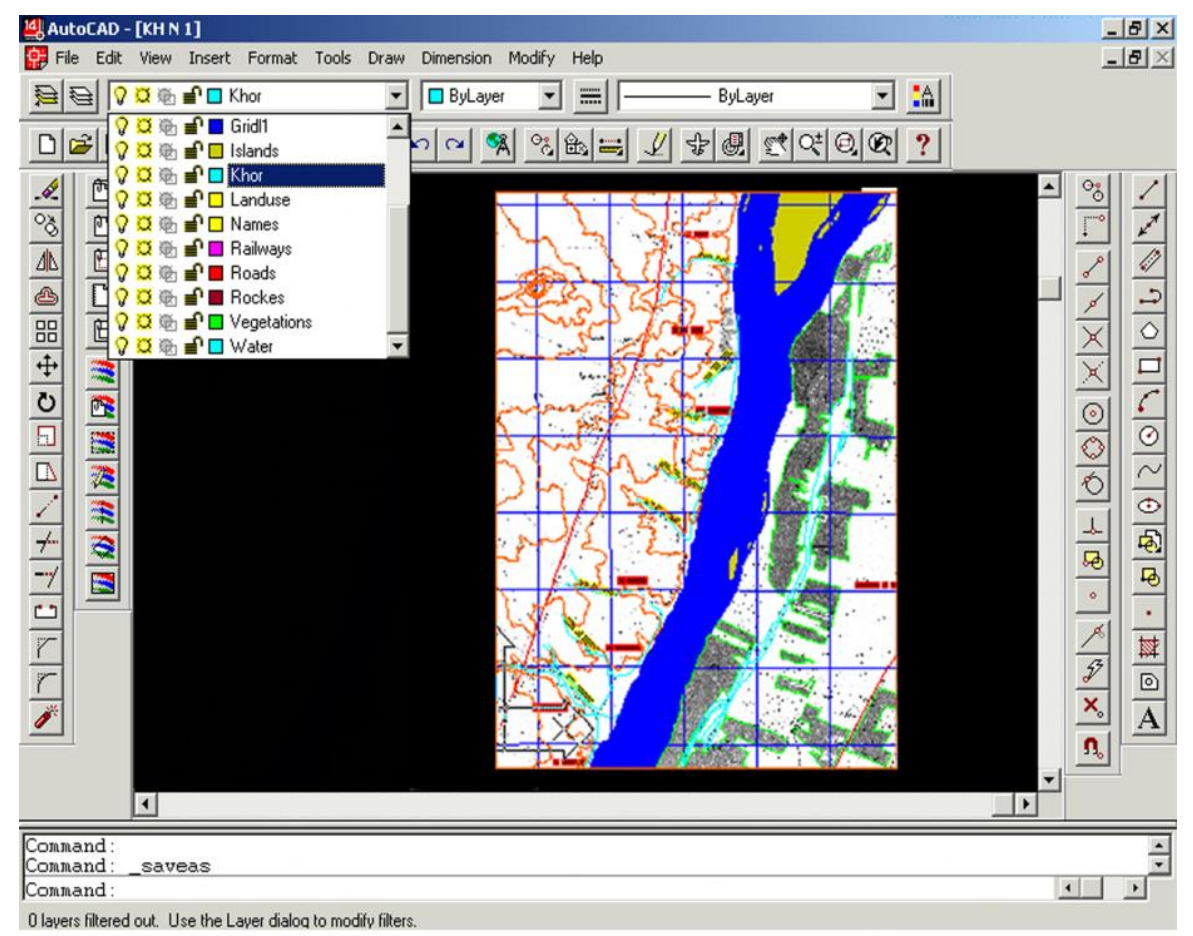

Figure (7) Different Auto-Cad layers of the Study Area 
$\underline{\text { Developing a Geographic Information System (GIS)... Dr.Fathi M. Mohammed Saied }}$

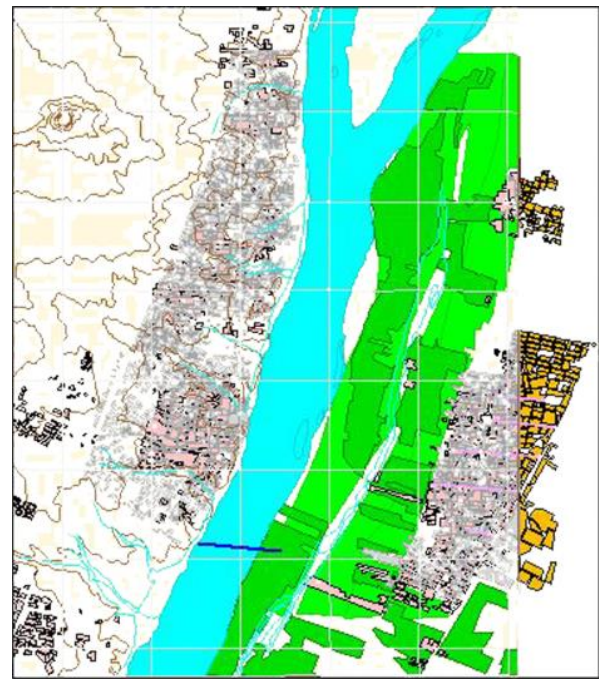

Figure (8 Urban Area Growth of the Study Area.

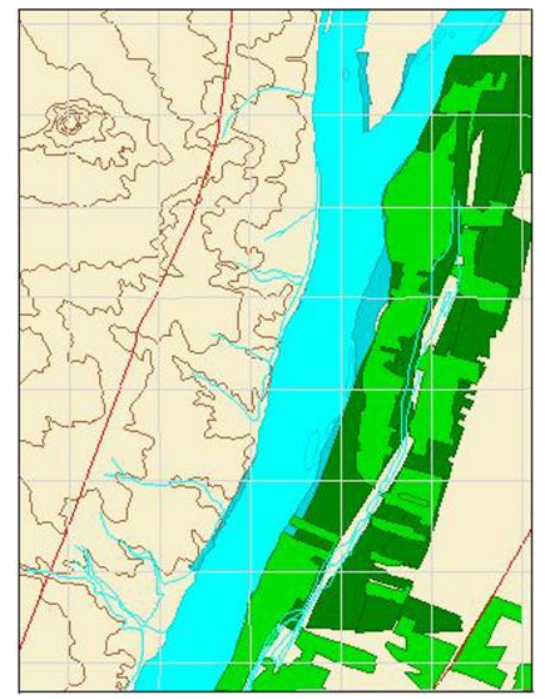

Figure (9) Vegetation Growth of the Study Area



Figure (10) Water Changes within the Study Area 
Eile Edit Yiew Iheme Graphics Window Help

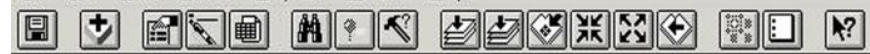

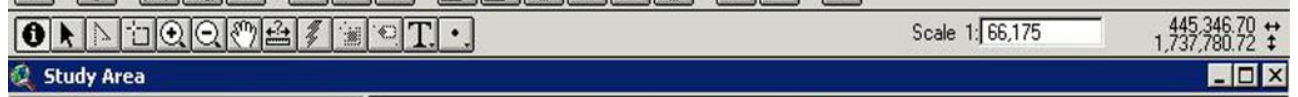

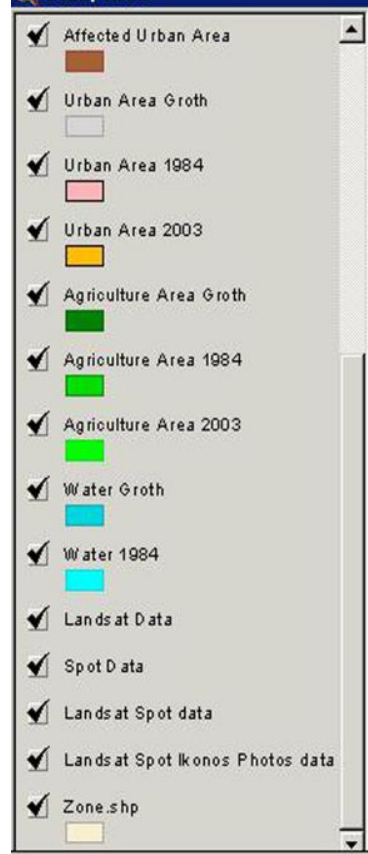

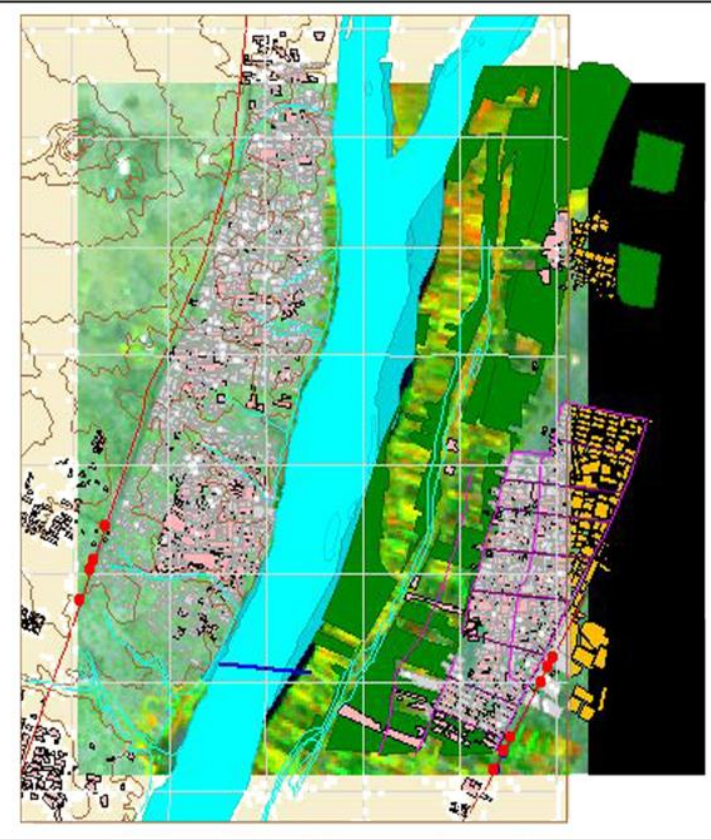

Figure (11) GIS Model of the Study Area 
$\underline{\text { Developing a Geographic Information System (GIS)... Dr.Fathi M. Mohammed Saied }}$

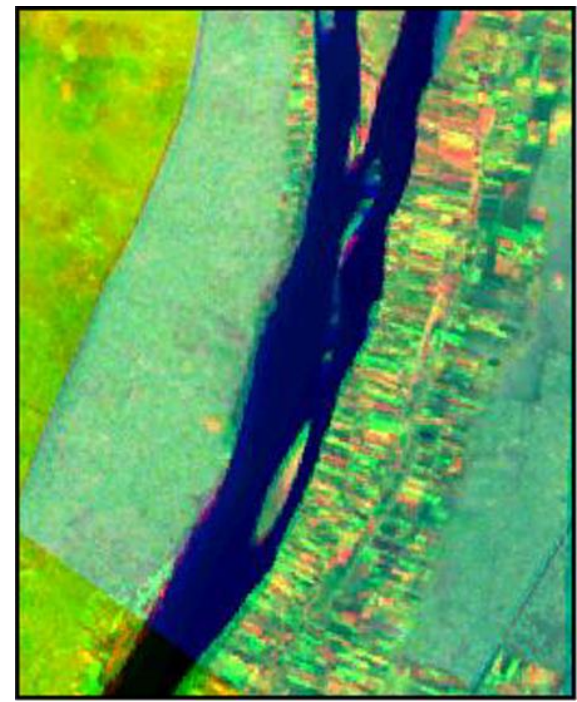

Figure 12 Combined Color Composite of the Study Area. RGB bands Indres4, Spotres3 and IKONOS2. 

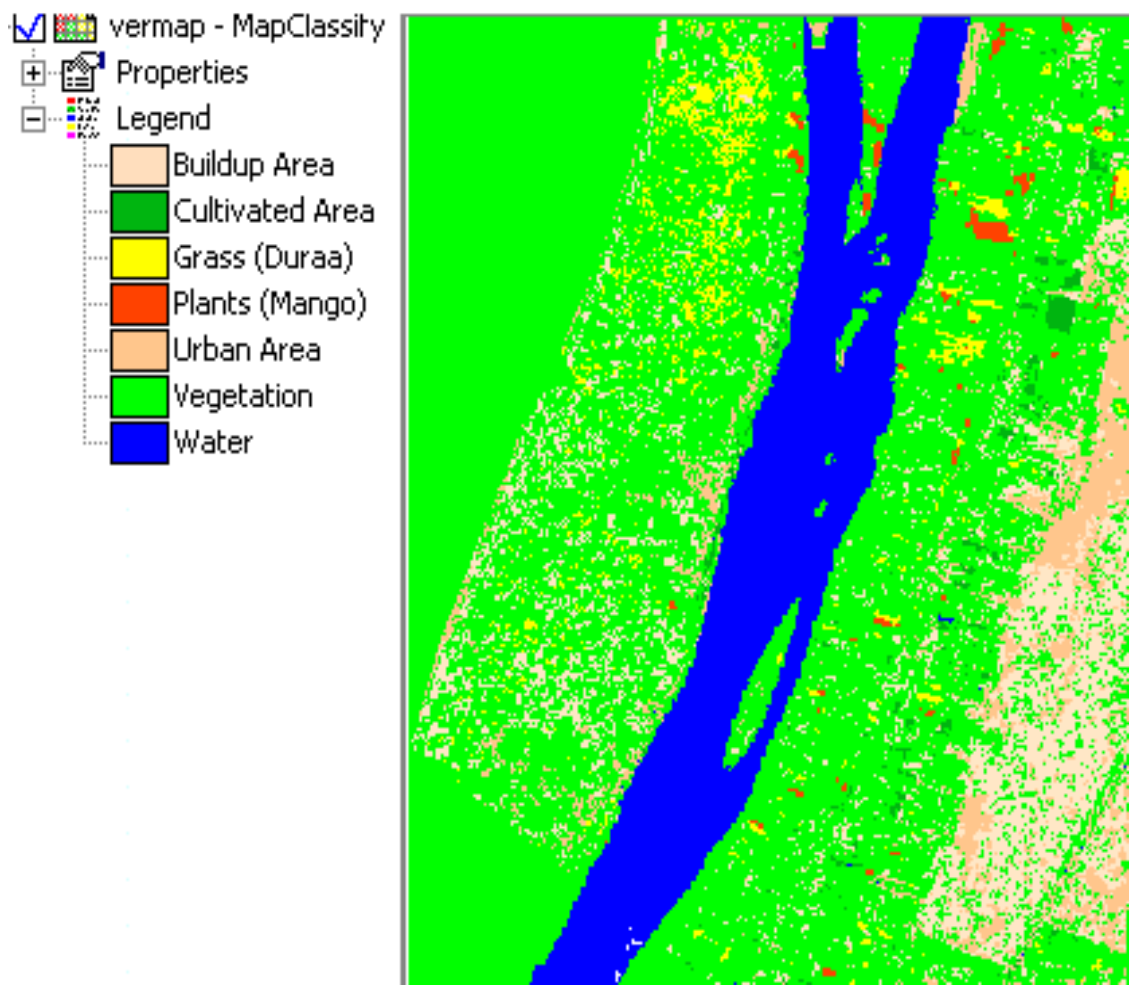

Figure (13) The Final Classified Image

Table (1) Results of the Ground Truth Checks

\begin{tabular}{|c|c|c|c|l|}
\hline $\begin{array}{c}\text { Sample } \\
\text { Plot No. }\end{array}$ & $\begin{array}{c}\text { Easting } \\
(\mathbf{m})\end{array}$ & $\begin{array}{c}\text { Northi } \\
\mathbf{n g}(\mathbf{m})\end{array}$ & $\begin{array}{c}\text { Class } \\
\text { Type }\end{array}$ & $\begin{array}{c}\text { Predominant } \\
\text { Feature }\end{array}$ \\
\hline 1 & 51271 & 738804 & Plants & Mango Trees \\
\hline 2 & 50956 & 739327 & Grass & Grass \\
\hline 3 & 51117 & 737012 & Plants & Mango Trees \\
\hline 4 & 51050 & 736526 & Grass & $\begin{array}{l}\text { Duraa } \\
\text { (Abusabean) }\end{array}$ \\
\hline 5 & 50879 & 736068 & Grass & $\begin{array}{l}\text { Duraa } \\
\text { (Abusabean) }\end{array}$ \\
\hline 6 & 50987 & 735356 & Land & Cultivated Area \\
\hline
\end{tabular}

